\title{
Using a smartphone in the learning process: the experience of the 2020 pandemic
}

\author{
Alexander Morozov ${ }^{1, *}$, Iskandar Mukhametzyanov ${ }^{2}$, and Olga Evdokimova ${ }^{3}$ \\ ${ }^{1}$ Research Institute of the Federal penitentiary service of Russia, Moscow, Russia \\ ${ }^{2}$ Institute of Educational Development Strategies of the Russian Academy of Education, Moscow, \\ Russia \\ ${ }^{3}$ Military Academy of Material and Technical Support (Penza branch), Russia
}

\begin{abstract}
In the last decade, the problem of using smartphones in education has become one of the most relevant topics of scientific discussion. As in the discussion of any other problem, it also identified both expressed supporters and equally serious opponents of the use of the gadgets in question in the educational process. Within the framework of this work, we present materials that reflect the expectations and concerns of teachers, doctors and other representatives of modern society on the topic we have identified. In different countries of the world, the pedagogical and hygienic significance and the impact of smartphones on the health and success of students' educational activities are evaluated in absolutely different ways. At the same time, the events of the past -2020 have identified the need to use smartphones, often almost as an alternative and forced measure.
\end{abstract}

\section{Introduction}

The experience of using smartphones for learning purposes that existed before 2020 can be assessed as episodic. With the beginning of the COVID-19 pandemic and the massive transition of educational organizations around the world to distance learning, the relevance of using smartphones as a means of students' access to educational communication and content has become unquestionable. The existing hygiene restrictions in the absence of alternative access devices have faded into the background, but their importance, with a significant increase in the student's contact time with a smartphone, has only increased. The mass use of smartphones led to not only a positive experience in terms of training, but also revealed a number of additional disadvantages of such a mass and long-term use of them. To maintain positive trends, it is necessary to find a compromise between the tasks of teaching and to avoid a significant side effect of smartphones on the health of students. In addition, it is necessary to adapt the existing educational content to the capabilities of smartphones and the limitations of the mobile Internet in the conditions of distance and mixed learning, since most students do not have alternatives for them in the near future.

\footnotetext{
* Corresponding author: doc_morozov@mail.ru
} 


\section{Research methodology}

The study presented by us was conducted in order to study, analyze and evaluate the use of smartphones in the modern format of education. Special attention was paid to the organizational, hygienic and medical aspects of the problem under consideration.

As the main research method, the authors used the analysis of publicly available reviews of the last decade and 2020, in particular, as the period of the most active use of smartphones in the framework of distance learning, due to the threat of the spread of COVID-19.

Smartphones during the COVID-19 pandemic have become so important in all areas of modern life that it is no longer possible to talk only about their harm [1,2]. At the same time, it is necessary to have a real understanding and deep awareness of the irrefutable fact that when we consider and analyze the issues caused by the educational process of minors at various stages of their education and, first of all, issues involving certain aspects of health care, it is pointless to deny or not attach any importance to the problem of an increasingly large-scale gadgetarization, which contributes not only to the emergence of Internet addiction in students, but also gadget addiction, which we noted and was the subject of special study in earlier publications.

Smartphones, as one of the most popular modern gadgets, are most widely used in medicine, are beginning to find their place in psychology and psychotherapy [3], and in education, they are often the only tool for accessing educational resources in the context of distance learning, which was clearly demonstrated throughout the civilized world during the forced transition of educational organizations at all levels to a distance learning format due to the threat of COVID-19 $[4,5]$.

Research conducted under the auspices of the American Academy of Pediatrics confirms the fact that virtual interaction of minors using various gadgets (or online relationships) is now part of typical adolescent behavior. An alarming signal is also the fact that teenage students often build their relationships exclusively in virtual reality on the Internet and have absolutely no experience of communication outside of social networks: digital communication for them is an everyday and already quite familiar norm of life, and the simple prohibition of smartphones as communication devices simply excludes them from life [6].

Considering the importance of the smartphone as one of the most important elements of the digital transformation of the entire system of modern education, we believe it is necessary to focus on the fact that, as a rule, in the modern family, it is the smartphone that is the personalized device for accessing the Internet, both for children and adults [7].

More complex and expensive devices: such as tablets, laptops, personal computers are not so easy to handle due to their smaller compactness and, accordingly, mobility (they can not be put in a pocket or in a small handbag), and, in addition, they differ in their price and are available in modern families, as a rule, in single copies, while the number of smartphones can be in greater numbers than the number of family members. In this regard, we consider it necessary to pay attention to the fact that today it is smartphones, and, more precisely, the features of their use in everyday life in terms of duration and frequency, are one of the main causes of intra-family conflicts [8].

Today, it is no longer a secret that there is a reliable link between the excessive use of smartphones and violations of both mental and physical health (this is especially true for underage students). Among the most frequent and pronounced symptoms, it is necessary to name the progressive deterioration of vision, the appearance and spread of pain in the neck and back, sleep disorders, etc. [9-11]. At the same time, modern smartphones have recently been increasingly used to stimulate and control physical activity. This phenomenon became especially popular during the period of self-isolation [12]. 
A number of studies have shown that higher smartphone addiction and higher fabbing (the habit of constantly being distracted by your gadget while talking to someone) are associated with high levels of depressive moods, with fabbing functioning as an intermediary between smartphone addiction and depression. The moderator of this mediation is loneliness, and the effect of mediation is asymmetrically dependent on gender:

- in men, high loneliness increases the mediating role of fabbing, which more markedly translates into depression;

- while in women, the analyzed mediating effect weakens with an increase in feelings of loneliness (fabbing is less strongly correlated with depression).

Applications on smartphones are increasingly used to correct depression and anxiety [13], headaches [14]. If necessary, the user contacts the application in the dialog mode, which provides short-term relief of depression and pain, but in the long term, the effect has not yet been studied. This situation, as well as many other modern components of the concept of mental health caused by the use of digital tools of activity, expands our understanding of the human psyche and its transformation in the digital environment and interactive digital communication.

\section{Results and discussion}

In the process of digitalization of the educational environment and the increasing priority of the use of distance learning technologies in the educational process, the use of various digital gadgets, especially smartphones, is significantly increasing [15]. At the same time, it should be emphasized that finding a reasonable compromise between the widespread use of smartphones for educational purposes and ensuring the guarantees of both mental and physical health of students is currently not possible [16-20].

Our analysis of the results of scientific research conducted to date allows us to make a preliminary conclusion that the prevalence and severity of smartphone addiction among students is rather weak, although it is noted that it is much higher among Apple smartphone users. At the same time, it should be noted that all, without exception, smartphones potentially pose a danger and threat to the health of users, especially minors [21, 22]. Researchers also note a higher dependence on gadgets in female representatives, which requires a certain alertness of parents and a whole range of additional measures to prevent its development, more targeted social support [23].

The steady skill of using mobile applications allows you to actively use various digital gadgets, including smartphones, for educational purposes continuously, taking into account the personal characteristics and individual properties of the psyche of a particular student, including the stability of attention, switchability, speed of perception of educational material, as well as the time spent on adapting the form of presentation of educational material to the needs of the student. In addition, a number of specialized applications designed to provide virtual psychological support for students can compensate for certain shortcomings and optimize educational activities. The weaknesses of the distance learning format, which are manifested, in particular, in the inability to implement practical laboratory work in the virtual process, are leveled by the use of special applications for smartphones that simulate the full-fledged laboratory work of the student [24].

At certain additional costs, taking into account the preparation of a special application, it becomes possible to implement the educational process through gamification, which is often a new method of teaching for most of the teaching staff [25]. In the context of solving the problems of psychological support of students, you can use the recommendations of the FDA USA on the use of the game EndeavorRX for the treatment of children with attention deficit hyperactivity disorder. 
As digital educational content, many teachers recommend using not only various mobile applications and other interactive educational resources in the form of audio and video, but also more active use of electronic books and textbooks. The use of a variety of digital educational content in the educational process allows students to more effectively develop information understanding skills and orientation skills in electronic libraries.

Active use of non-educational resources (payment tools, electronic diary, security elements of the educational organization itself) expands the capabilities of the student and his parents in managing the educational trajectory of the student. Becoming a part of a single educational and controlled space of an educational organization, the student becomes focused on the use of safe digital educational resources, on the implementation of educational activities within a safe information and educational environment.

The participation of parents in the digital transformation of education allows them to implement communication in the usual conditions for modern students. It should be noted that at the same time, the educational organization gets the opportunity for daily operational personal communication with both students and their parents.

When evaluating the results of the effectiveness of the use of smartphones in the educational process, we consider it necessary to pay attention to the meta-analysis of more than a hundred scientific publications in the twenty-year period from 1993 to 2013 [26]. According to the study, the analysis of the content of publications on the use of various mobile devices in the field of education, presented in peer-reviewed publications, led to the conclusion that the overall effect of their use is higher than when using desktop computers. Another interesting conclusion is that the above effect does not depend on the age of the students. And finally, the main conclusion is that the highest effect is found when using smartphones.

One of the most significant advantages of smartphones is that they have an individually configured interface that is friendly to the student, and the ability to access information from anywhere thanks to the mobile Internet. The positive effect increases if the student uses special digital educational resources and content originally prepared for the capabilities of smartphone screens.

Internet access is currently implemented, to a large extent, in the form of a mobile application available in digital gadgets. Modern digital educational resources with multimedia, elements of VR (virtual reality) and AR (augmented reality) require a significant amount of traffic and are hardly applicable in these conditions [27].

The quality of the Internet in traditional networks is extremely variable, and it is usually very organic in terms of speed or cost. This, in turn, reduces the possibility of its use by students for educational purposes. A number of studies have shown that students are ready to implement the learning process in a remote format and with the use of digital resources, but their main device is a smartphone, and Internet access is mobile, respectively, with traffic restrictions. The use of digital resources based on multimedia by students in these conditions is not possible [28].

Hygiene issues when using smartphones are no less important during the pandemic. The urgent recommendations of the sanitary services regarding the disinfection of everything that a person comes into contact with have also found a response among smartphone users. All smartphones have bacterial and viral contamination, about $7 \%$ have contamination with pathogenic microbes for humans [29]. Moreover, the contamination is higher on smartphones, and not on mobile phones, since smartphones are used more often and longer [30]. A number of studies show that in January 2020, only $18.5 \%$ of users disinfected their smartphone with special means at least once a week, $14 \%$ - once a month. However, more than $60 \%$ have never done it. But by the beginning of the second wave of the pandemic, in August $2020,40.1 \%$ of users had already disinfected their smartphone once a week, and only $45.9 \%$ of users confirmed their refusal to disinfect [31]. 
When we talk about disinfection of smartphones in the context of COVID-19, it is necessary to remember that this is, first of all, an electronic device, and with active disinfection it can fail. Therefore, the use of traditional hygiene recommendations may be irrational [32]. It is preferable to use special liquids and wipes for electronics and UV sterilizers in the form of special cases or lamps. Other means, along with disinfection of the smartphone, will significantly affect its appearance and consumer properties.

\section{Conclusions}

The use of multimedia in modern digital educational resources requires not only the quality and a significant amount of communication component, but also the quality of display tools. The size of the device's screen, its resolution, and so on are important. In addition, many educational resources are initially designed for devices with a large screen diagonal (personal computers and laptops) and are not adapted for tablets and smartphones. In terms of the use of smartphones as Internet access devices, it is necessary to remember that for most students this is not only a priority tool, but also the only one. It can be banned for educational purposes, but this will also take away the very possibility of learning. Unfortunately, in terms of cost-effectiveness, it is still impossible to replace a smartphone for a significant part of children from families with a limited budget.

\section{References}

1. A. Morozov, XXIV International Scientific and practical conference: Effective counteraction to crime in the context of globalization: problems and prospects, 126 (2020)

2. V. Saladino, D. Algeri, V. Auriemma, Frontiers in Psychology, 11 (2020)

3. E. Humer, C. Pieh, M. Kuska, A. Barke, B. Doering, K. Gossmann, R. Trnka, P. Tavel, T. Probst, Int. J. Environ. Res. Public Health, 17, 4811 (2020)

4. I. Ganicheva, A. Morozov, Education and Law, 12, 238(2020)

5. K. Iyengar, G. Upadhyaya, R. Vaishya, V. Jain, Diabetes \& Metabolic Syndrome: Clinical Research \& Reviews (2020)

6. E. Abi-Jaoude, K. Naylor, A. Pignatiello, Canadian Medical Association Journal, 192(6), E136 (2020)

7. J. Radesky, H. Weeks, R. Ball, A. Schaller, S. Yeo, J. Durnez, M. Tamayo-Rios, M. Epstein, H. Kirkorian, S. Coyne, R. Barr, Pediatrics, e20193518 (2020)

8. C. Kildare, W. Middlemiss, Computers in Human Behavior, 75, 579 (2017)

9. K. Mathew, M. Walarine, Journal of Ideas in Health, 3 (2020)

10. A. Irawan, D. Dwisona, M. Lestari, Journal Bimbingan dan Konseling (E-Journal), 7(1), 53(2020)

11. X. Dong, M. Ding, W. Chen, Z. Liu, X. Yi, Int. J. Environ. Res. Public Health, 17, 8043 (2020)

12. L. Crosby, O. Bonnington, Sociol Health, 42, 925 (2020)

13. M. Minen, T. Gumpel, S. Ali, F. Sow, K. Toy, The Journal of Head and Face Pain, 60 (2020)

14. L. Laranjo, D. Ding, B. Heleno, B. Kocaballi, J. Quiroz, H. Tong, D. Bates, British Journal of Sports Medicine, 102892 (2020) 
15. A. Ivanova, O. Gorbaniuk, A. Błachnio, A. Przepiórka, N. Mraka, V. Polishchuk, J. Gorbaniuk, Psychiatric Quarterly (2020)

16. T. Bashkireva, A. Bashkireva, A. Morozov, A. Evdokimova, M. Apsite, ISCDE 2020, 156, 159 (2020)

17. S. Kuldip, M. Manvin, N. Samah, Asian Social Science (2018)

18. J. Huckins, A. daSilva, W. Wang, E. Hedlund, C. Rogers, S. Nepal, J. Wu, M. Obuchi, E. Murphy, M. Meyer, D. Wagner, P. Holtzheimer, A. Campbell, Journal of medical Internet research, 22 (6), e20185 (2020)

19. A. Morozov, A. Tereshchenko, Materials of the annual international scientific and practical conference: Ecological pedagogy and psychology of health: problems, prospects of development, 127 (2014)

20. I. Mukhametzyanov, Pedagogical Informatics, 6 (2011)

21. A. Rudkovska, W. Sui, J. Irwin, Journal of American College Health, 1 (2020)

22. I. Mukhametzyanov, Medical aspects of informatization of education (2017)

23. Y. Jeong, Ju. Oh, Journal of Addictions Nursing, 31, 1 (2020)

24. C. Lellis-Santos, F. Abdulkader, Advances in Physiology Education, 44, 4. (2020)

25. S. Felszeghy, S. Pasonen-Seppänen, A. Koskela, P. Nieminen, K. Härkönen, K. Paldanius, A. Mahonen, BMC Medical Education, 19 (1) (2019)

26. Y. Sung, K. Chang, T. Liu, Computers \& Education, S0360131515300804 (2015)

27. S. O'Connor, T. Andrews, Smartphones and mobile applications (apps) in clinical nursing education: A student perspective. Nurse Education Today (2018)

28. E. Arthur-Nyarko, D. Agyei, J. Armah, Educ Inf Technol, 25, 2987 (2020)

29. A. Morozov, I. Mukhametzyanov, People and education, 2 (51), 48 (2017)

30. D. Ozkaya, S. Ayhan, C. Yazar, O. Nahya, P. Kılıcdag1, A. Azap, Infectious Diseases and Clinical Microbiology, 2 (2020)

31. Do you clean your phone now? How coronavirus has changed us (or not), https://www.zdnet.com/article/do-you-clean-your-phone-now-how-coronavirus-haschanged-us-or-not/

32. World Health Organization. Cleaning and disinfection of environmental surfaces in the context of COVID-19, https://apps.who.int/iris/rest/bitstreams/1277966/retrieve 